\section{International Scientific Journal Theoretical \& Applied Science}

Natalia Vladimirovna Batciun

Associate Professor,

Department of World Economy

Irkutsk National Research Technical University,

Russia

nbatsun@mail.ru

Year: 2015 Issue: 04 Volume: 24

Published: $30.04 .2015 \quad$ http://T-Science.org

Section 31. Economic researches, finance, innovations, risk management.

\title{
COMPETITIVE FACTORS OF SUCCESS OF BUSINESS: IMAGE AND FINANCIAL APPEAL
}

Abstract: For competitiveness increase business has to bear social responsibility and build positive image. Such strategy promotes increase of financial appeal to financial institutions.

Key words: business, competitiveness, image, social responsibility, financial appeal.

Language: Russian

Citation: Batciun NV (2015) COMPETITIVE FACTORS OF SUCCESS OF BUSINESS: IMAGE AND FINANCIAL APPEAL. ISJ Theoretical \& Applied Science 04 (24): 131-134.

Soi: http://s-o-i.org/1.1/TAS*04(24)21 Doi: crossef http://dx.doi.org/10.15863/TAS.2015.04.24.21

\section{КОНКУРЕНТНЫЕ ФАКТОРЫ УСПЕХА БИЗНЕСА: ИМИДЖ И ФИНАНСОВАЯ ПРИВЛЕКАТЕЛЬНОСТЬ}

Аннотация: Для повышения конкурентоспособности бизнес должен нести социальную ответственность и выстраивать положительный имидж. Такая стратегия способствуют повышению финансовой привлекательности для финансовых институтов.

Ключевые слова: бизнес, конкурентоспособность, имидж, сочиальная ответственность, финансовая привлекательность

Мировая практика предпринимательства давно показала, что благоприятное представление о фирме способствует лучшему спросу на ее товары или услуги. Интеграционные процессы в мировой экономике способствуют повышению конкуренции как на мировом рынке, так и на уровне национальных рынков. В таких условиях бизнесу необходимо находить всё новые и новые факторы конкурентоспособности. К таким относительно новым факторам, для российского предпринимательства относятся имидж и финансовая привлекательность. Данные факторы играют немаловажную роль не только на национальном, что само по себе уже радует, но и в значительной мере при обращении российского бизнеса к иностранным инвесторам. Финансовые и инвестиционные институты, среди многих прочих аспектов, принимают во внимание социальные и экологические последствия реализации кредитуемых проектов. Такой подход предоставляет значительные возможности для продвижения идей развития экологически и социально ответственного управления бизнесединицами. В частности в рамках специальной экспертизы существует обязательное присутствие экологического раздела, где решаются следующие вопросы:

- Устойчивое развитие и использование возобновляемых природных ресурсов.

- Защита здоровья человека, культурного достояния и биоразнообразия, в том числе подвергающихся опасности биологических видов и экосистем.

- Использование опасных материалов.

- Основные источники опасности.

- Охрана труда и техника безопасности на производстве.

- Противопожарные мероприятия и безопасность жизни.

- Социально-экономические последствия.

- Приобретение и использование земельных участков.

- Вынужденное переселение.

- Последствия для коренного населения и общин. 
- Совокупные последствия существующих проектов, предлагаемого проекта и предполагаемых будущих проектов.

- Участие затрагиваемых проектом сторон в его разработке, анализе и реализации.

- Рассмотрение

альтернатив, предпочтительных в экологическом и социальном плане.

- Эффективное производство, доставка и использование энергии.

- Предотвращение загрязнения и минимизация отходов, меры контроля за уровнем загрязнения (жидкие промышленные отходы и выбросы в воздух), работа с твердыми и химическими отходами [1].

Кроме того, данная процедура позволяет оценить с экологической точки зрения состояние производства, оборудования, технологических процессов, территории, исходного сырья и готовой продукции на всех стадиях производства. В результате такого всестороннего анализа может быть подготовлено квалифицированное экоаудиторское заключение об экологической безопасности производства в целом и экологической чистоте выпускаемой продукции [2].

Степень соответствия реального производства экологическим критериям, учитывается при принятии решения о выделении кредита, при оценке экологических рисков и определении экологического имиджа предприятия или корпорации.

Финансовая инициатива Программы ООН по окружающей среде (UNEP FI) и Всемирный фонд дикой природы (WWF) предложили внедрить в корпоративную практику российских финансовых компаний ряд добровольных принципов ответственного инвестирования. Проект развития механизмов устойчивого финансирования в России, изначально включал в себя цель, задачи, принципы ответственного инвестирования на период до 2012 г. [3]

Российский бизнес для закрепления на европейских и североамериканских рынках, должен предложить своим партнерам эффективную и адекватную российским реалиям систему социальной ответственности, в частности и в области экологического информирования. Опыт показывает, что экологические рейтинги регионов, отраслей, компаний и предприятий в силу объективности, простоты и эффектной подачи сравнений, привлекают массовое внимание и обладают потенциалом реального влияния на выбор продукции или партнеров по бизнесу. Необходимо обеспечить общество достаточным массивом справочной рейтинговой информации [4].
В Европе ведется список европейских загрязнителей (EPER - European Pollution Emission Register) атмосферы и водоемов. Эти сведения постоянно обновляются, удобно сгруппированы, доступны для любого пользователя Интернета. Общую картину помогает представить интерактивная карта и информационные индикаторы. [5]

При высокой социальной активности потребителей есть риск отказа даже от качественных товаров, в случае нарушения бизнесом интересов общества. Основная идея создаваемой системы «экологической прозрачности» российского бизнеса в том, чтобы содействовать росту капитализации и привлекательности для инвесторов тех компаний, которые проводят эффективную экологическую политику.

В этом случае бизнес вынужден идти на уступки, что и явилось предпосылкой возникновения так называемой институциональной рекламы, т. е. рекламы самих институтов общества, а «Public Relations», как способ общения бизнеса с потребителями и обществом в целом. Институциональная реклама логично переросла в современную корпоративную рекламу. Таким образом, бизнес постоянно доказывает обществу свою «социальную рентабельность», что впрочем, является обязательным условием его существования, ведь развитие бизнеса напрямую связано с развитием общества. Корпоративная реклама сообщает о том, какие средства та или иная фирма вкладывает в наиболее социально значимые объекты. Чаще всего это в охрану окружающей среды, создание рабочих мест, помощь людям с ограниченными возможностями, детям-сиротам и т. д. Предприниматели громко заявляют о своих программах, ориентированных на социальные нужды людей и напрямую не связанных с выпуском товаров или предоставлением услуг. Участие фирмы в социальных проектах, не связанных непосредственно с деятельностью фирмы, многократно укрепляет ее имидж. Существует множество способов создания и поддержания позитивного имиджа компании. Среди них социальные $\quad$ PR-технологии: благотворительность, спонсорство, долгосрочные социальные программы [6].

Показательна одна из реклам фирмы Ford: «Главное занятие Форда благотворительность, а производство автомобилей - это побочный бизнес, необходимый для того, чтобы осуществлять эту благотворительность». Не только зарубежный, но и российский опыт ведения бизнеса говорит о пристальном внимании к имиджу и репутации бизнес-структуры, создания ее образа у 
потребителей, клиентов, поставщиков, инвесторов, партнеров является основным стратегическим приоритетом. Приведем лишь несколько примеров. Миссия Иркутской электросетевой компании звучит так: «Мы делаем жизнь человека в Приангарье комфортной и благополучной, создаем фундамент для динамичного развития региона» [7].

При определении стратегии своего развития и текущей деятельности ГМК «Норильский никель» исходит из того, что обязательным условием устойчивого и эффективного развития бизнеса является неуклонное следование принципам социальной и экологической ответственности [8].

Приверженность данной политике отражена и в миссии Торгово-промышленной Палаты России. В программе деятельности ТПП РФ говорится: «ТПП РФ ...проводит в своей деятельности политику социальной ответственности предпринимателей и их объединений, придерживаясь международных принципов, зафиксированных в Глобальной инициативе $\mathrm{OOH}$ и в рекомендациях Международной организации предпринимателей, в конвенциях и рекомендациях МОТ [9].

Список можно продолжать, но выводы таковы, что имидж в настоящее время стал одним из основных элементов обеспечения конкурентоспособности бизнес-единицы и её финансовой привлекательности.

Сегмент социально ответственных инвестиций (СОИ) за последние десятилетие на рынке ценных бумаг, значительно вырос. Наиболее распространённый подход к СОИ - это «просеивание», т.е. выбор для инвестиционного портфеля бумаг тех компаний, которые отвечают заданным социальным или экологическим критериям [10].

Невнимательное отношение к имиджу своей фирмы может привести к снижению конкурентоспособности бизнеса.

Альфред Нобель сказал: «Хорошая репутация более важна, чем чистая рубашка. Рубашку можно выстирать, репутацию никогда». На создание позитивного имиджа уходят многие годы, а вот разрушить можно легко, если компания не имеет четко сформулированного структурированного и всеобщего набора процедур и методов возможных действий в конкретных ситуациях, в том числе и кризисных. Необходимо тщательно выбирать средства построения имиджа, с учётом различных характеристик целевой аудитории (экономических, психологических, эстетических...). Конечно, не надо забывать о качестве товаров и услуг, оно учитывается по умолчанию.
Одной из причин объясняющих, все ещё низкий имидж предпринимательства в нашей стране является инерция массового сознания. Это вполне объяснимо учитывая нашу историю. На протяжении нескольких десятков лет в нас воспитывался дух неприемлемости предпринимательства, частной собственности, да и самих рыночных отношений. Накопление капитала, перераспределение собственности всё это происходило на наших глазах и очень тяжело переживалось обществом.

Второй причиной можно назвать и некоторые действия самого российского предпринимательства, формирующие негативный имидж предпринимательства в обществе в целом. Но давайте помнить, что наш бизнес ещё очень молод, а молодости свойственно ошибаться.

Третья причина - определенная избирательность наших средств массовой информации в освещении деятельности отечественных предпринимателей, подкрепляет распространенное представление о том, что предпринимательство - дело нечистое.

Хотелось бы отметить и влияние неудачной рекламы. Население нашей страны достаточно доверительно относится к рекламе. А значит, может судить о репутации фирмы и в целом о российском предпринимательстве, прежде всего по рекламе. И опять же таки инертность сознания, следствие воспитания нас на протяжении многих десятилетий в духе «равных возможностей» заставляет наших граждан болезненно воспринимать рекламу, рассчитанную лишь на богатых. Впрочем, к этому стоит ещё добавить и низкий уровень жизни населения. В России чистый семейный скорректированный доход после уплаты налогов на душу населения в среднем составляет 17230 долларов США в год, что меньше, чем в среднем по ОЭСР (23938 долларов США в год). В то же время имеется значительная разница в доходах между самыми богатыми и самыми бедными слоями населения - доход 20\% наиболее обеспеченной части общества в шесть раз превышает доход $20 \%$ самых бедных его представителей [11]. В настоящее трудно оценить изменения этих показателей на фоне происходящих событий.

Один из путей, возможно один из самых простых - создание социальной рекламы, в которой показать, что наших предпринимателей заботит не только прибыль, но и решение проблем, которыми озабочено общество в целом.

И, наконец, четвертая причина - отсутствие у наших предпринимателей чёткого понимания социальной ответственности бизнеса перед обществом. 
Подводя итоги, необходимо отметить, что механизм управления имиджевой политикой есть совокупность средств воздействия и технологий.

Механизм управления имиджевой политикой организации основывается на базовых принципах, включающие следующие основные направления:

- организация взаимодействия с клиентами;

- налаживание взаимодействия с сотрудниками;
- упрочнение отношения государственными структурами;

- поддержание отношений со СМИ;

- корректировка дезинформации.

Формирование и поддержание имиджа процесс довольно сложный, длительный и затратный, исходя из этого, при разработке имиджевой политики важно осуществлять долгосрочное стратегическое планирование.

\section{References:}

1. (2011) Copyright (C) Principov Ekvatora 2011. Available: http://www.equator-principles.com (Accessed: 17.04.2015).

2. Boboshko VI (2006) Ekologicheskaya etika i predprinimatelskaya deyatelnost. Priroda i obshhestvo v novom tysyacheletii. Globalizaciya i regionalnye ekologoekonomicheskie problemy. mezhd. konf. Ross. Otd. mezhd. obshhestva ekologicheskoj ekonomiki. Saratov, 2006.

3. (2015) Proekt «Razvitie mexanizmov ustojchivogo finansirovaniya v Rossii». Available:

www.wwf.ru/data/pub/business/sustainable fin ancing.pdf (Accessed: 17.04.2015).

4. (2015) Spravochnik po ekologicheskim rejtingam rossijskogo biznesa. Available: http://biodat.ru/db/mon/rating.htm (Accessed: 17.04.2015).

5. (2015) Evropejskoe agentstvo po okruzhayushhej srede. Available: http://prtr.ec.europa.eu/ $\quad$ (Accessed: 17.04.2015).
6. Feofanov O (2000) Reklama. Novye texnologii v Rossii PITER Sankt-Peterburg Moscow•Xarkov $\bullet$ Minsk 2000.

7. (2015) oficialnyj sajt Irkutskoj elektrosetevoj kompanii. Available: http://www.iesk.irkutskenergo.ru/ (Accessed: 17.04.2015).

8. (2015) Oficialnyj sajt gruppy Norilskij nikel Available: http://www.nornik.ru/kompaniya/okompanii/missiya-i-strategiya (Accessed: 17.04.2015).

9. Informacionnyj centr «Mecenat» Available: http://www.maecenas.ru/doc/2003_4_7.html (Accessed: 17.04.2015).

10. (2015) Spisok S\&P500 kompanii. Available: http://en.wikipedia.org/wiki/List_of_S\%26P 50 0_companies (Accessed: 17.04.2015).

11. (2015) sajt «Vash Indeks luchshej zhizni» Available:

http://www.oecdbetterlifeindex.org/ru/countries /russian-federation-ru/ (Accessed: 17.04.2015). 